CONTRIbution from the Chemical Laboratory of HaRvard University.]

\title{
ADDITION REACTIONS OF PHOSPHORUS HALIDES. III. THE REACTION WITH DIBENZAL-ACETONE AND CINNAMYLIDENE-ACETOPHENONE.
}

By James B. Conant, Albert H. Bump and Harold S. Holt.

Received April 4, 1921.

Both phosphorus trichloride and phosphenyl chloride (phenyl-dichlorophosphine) readily combine with the conjugated system of simple unsaturated ketones such as benzal-acetophenone. The addition product reacts with glacial acetic acid and forms a saturated keto-phosphonic acid. ${ }^{1}$ As a continuation of the study of these reagents on conjugated systems, two di-olefenic aketones-dibenzal-acetone and cinnamylidene acetophenone-have been investigated. Keto-phosphonic acids were obtained by the action of phosphorus trichloride on both substances but the yields were unsatisfactory. Phosphenyl chloride gave much better results; the yields were fairly good and the acids obtained were high melting, crystalline substances. This reagent, therefore, seems to be a promising one for the further investigation of unsaturated ketones.

Both reagents combine with only one of the two conjugated systems in dibenzal-acetone; it was not possible to obtain diphosphonic acids such as might be formed by the addition of a second molecule of the reagent. The addition to cinnamylidene-acetophenone takes place in the 1,4 position although there is the possibility of 1,6 addition with this compound. This is in agreement with the results obtained by adding other reagents to this same substance.

\section{The Reaction with Dibenzal-acetone.}

The reaction between this ketone and the phosphorus halide was carried out in glacial acetic acid; no attempt was made to isolate any intermediate products, as the mechanism of the reaction has already been established. A dibasic keto-phosphonic acid (I) was obtained by the use of the trichloride and a monobasic acid (II) by the use of phosphenyl chloride.

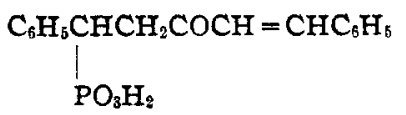

(I).

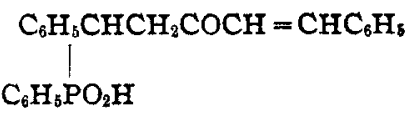

(II).

Both of these substances are unsaturated; they combine with two atoms of bromine and are readily oxidized with the formation of benzaldehyde. This establishes their structure. The monobasic acid (II) when oxidized with ozone yielded, besides benzaldehyde, a dibasic acid of the formula $\mathrm{C}_{6} \mathrm{H}_{3} \mathrm{CH}\left(\mathrm{C}_{6} \mathrm{H}_{5} \mathrm{PO}_{2} \mathrm{H}\right) \mathrm{CH}_{2} \mathrm{COOH}$. The first decomposition product of the

1 Tais JourNaI, 42, 830 (1920). 
ozonide, an $\alpha$-ketonic aldejayde, could not be isolated, and under the conditions of the experiment, was apparently transformed into the saturated acid with one less carbon atom.

The dibromides which were formed from both acids (I) and (II), very readily lost hydrobromic acid when treated with alkaline reagents and formed unsaturated monobromo acids. The structure of these monobromides is as shown below (III and IV).

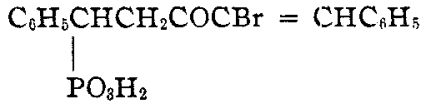

(III).

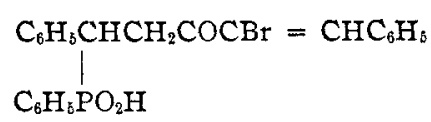

(IV).

This structure is in accord with the well-known ease with which $\beta$-bromoketones lose hydrobromic acid when treated with alkaline reagents.

\section{$\mathrm{C}_{6} \mathrm{H}_{3} \mathrm{CH} \quad\left(\mathrm{C}_{6} \mathrm{H}_{5} \mathrm{PO}_{2} \mathrm{H}\right) \quad \mathrm{CH}_{2} \mathrm{COCHBrCHBrC} \mathrm{H}_{5}-\mathrm{HBr} \rightarrow \mathrm{C}_{6} \mathrm{H}_{5} \mathrm{CH}\left(\mathrm{C}_{6} \mathrm{H}_{5} \mathrm{PO}_{2} \mathrm{H}\right.$ $\mathrm{CH}_{2} \mathrm{COCBr}=\mathrm{CHC}_{6} \mathrm{H}_{5}$.}

The only other possibility is that the dibromide is not a real addition product but is formed by the substitution of one of the hydrogens of the $\mathrm{CH}_{2}$ group and subsequent addition of hydrobromic acid to the double bond. This hydrobromic acid would then be readily removed by alkaline reagents and the monobromides would have the structures represented by (V) and (VI).

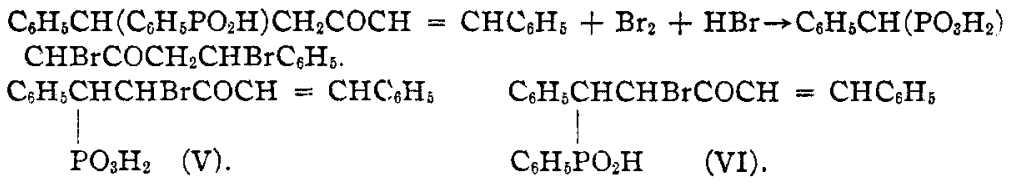

In view of the somewhat unusual behavior of these monobromides with alkaline reagents, it was necessary to decide definitely between these alternative formulas. This was accomplished by oxidation with ozone. The dibasic monobromide (III or V) yields a tribasic acid, $\mathrm{C}_{6} \mathrm{H}_{5} \mathrm{CH}$ $\left(\mathrm{PO}_{3} \mathrm{H}_{2}\right) \mathrm{CH}_{2} \mathrm{COCO}_{2} \mathrm{H}$; on heating, it is transformed into a substance the analysis of which is in agreement with the formula $\mathrm{C}_{6} \mathrm{H}_{5} \mathrm{CH}\left(\mathrm{PO}_{3} \mathrm{H}_{2}\right)$ $\mathrm{CH}_{2} \mathrm{CO}_{2} \mathrm{H}$. Such acids could result only by the oxidation of a compound represented by Formula. III; a substance with the alternative structure (V) would yield an $\alpha$-bromo acid. Furthermore, the first decomposition product of the ozonide of a substance of Structure III should be an acid bromide. This could not be isolated but its presence was shown by the fact that hydrobromic acid was formed when the ozonized solution was shaken with cold water.

In the case of the other monobromo acid (IV or VI), hydrobromic acid was formed as before, but the ketonic acid could not be isolated. Its decomposition product $\mathrm{C}_{6} \mathrm{H}_{5} \mathrm{CH}\left(\mathrm{C}_{6} \mathrm{H}_{5} \mathrm{PO}_{2} \mathrm{H}\right) \mathrm{CH}_{2} \mathrm{COOH}$, however, was obtained and found to be identical with the acid formed by oxidation of the 
keto-phosphonic acid (II). This establishes the structure of the monobromide as being that represented by Formula IV. The addition of bromine to the unsaturated acids thus proceeds normally.

\section{Reactions of the Monobromides.}

Certain $\beta$-bromophosphonic acids which have been previously described ${ }^{1}$ are very unstable in the presence of aqueous alkaline reagents. For example, the bromo acid prepared from benzal-acetophenone is decomposed even by sodium hydrogen carbonate solution forming the unsaturated ketone, sodium bromide and sodium phosphate.

$\mathrm{C}_{6} \mathrm{H}_{6} \mathrm{CH}\left(\mathrm{PO}_{3} \mathrm{H}_{2}\right) \mathrm{CHBrCOC}_{6} \mathrm{H}_{6} \rightarrow \mathrm{C}_{6} \mathrm{H}_{6} \mathrm{CH}=\mathrm{CHCOC}_{6} \mathrm{H}_{6}+\mathrm{HBr}+\mathrm{HPO}_{3}$

It was therefore of interest to investigate the action of alkaline reagents on. the bromides prepared in this research. The dibromide dissolves in cold sodium hydrogen carbonate or carbonate solution without decomposition. On warming these solutions, however, decomposition takes place, the odor of benzaldehyde becoming at once apparent. Both dibromides can be transformed into monobromides as previously stated. This is accomplished by the use of one equivalent of potassium hydroxide, or better by an excess of potassiurn acetate.

The monobromo acids readily dissolve in sodium carbonate solution without decomposition. Aqueous potassium hydroxide solutions of the acids, however, decompose quite rapidly with the formation of benzaldehyde and the removal of bromine and the phosphorus radical. No other definite products could be isolated with the monobasic acid (IV). In the case of the dibasic acid (III), however, a small amount of dibenzalacetone was formed. The use of alcoholic potassium hydroxide solution increased the yield of unsaturated ketone to $25 \%$. This formation of the unsaturated ketone is most surprising. No evidence for the mechanism of the reaction is at hand but in view of the results obtained with the $\beta$ bromo acids it seems probable that a simultaneous removal of the bromine atom and the phosphate group is involved. If this elimination took place from the enol form of the keto-acid, it would be a usual case of 1,4 elimination-the reverse of 1,4 addition. Subsequent ketonization of the product would form dibenzal-acetone. Considering the fact that this decomposition takes place under conditions which would favor the formation of the enol form, this mechanism seems probable.

$\mathrm{C}_{6} \mathrm{H}_{6} \mathrm{CH}\left(\mathrm{PO}_{3} \mathrm{H}_{2}\right) \mathrm{CH}=\mathrm{COHCBr}=\mathrm{CHC}_{6} \mathrm{H}_{6} \rightarrow \mathrm{C}_{6} \mathrm{H}_{5} \mathrm{CH}=\mathrm{CHCOH}=\mathrm{C}=\mathrm{CHC}_{6} \mathrm{H}_{5}+$ $\mathrm{HBr}+\mathrm{HPO}_{3}$

$\rightarrow \mathrm{C}_{6} \mathrm{H}_{5} \mathrm{CH}=\mathrm{CHCOCH}=\mathrm{CHC}_{6} \mathrm{H}_{5}$.

(intermediate enol)

The formation of benzaldehyde as another product of this reaction can be attributed to the further decomposition of the unsaturated enol form. The easy decomposition of both these dibromides with the formation of benzaldehyde must be in some such way connected with the presence of the 
bromine atom. The unsaturated keto-phosphonic acids themselves are not decomposed under parallel conditions.

\section{Reaction with Cinnamylidene-acetophenone.}

The results obtained with the trichloride and this ketone were very unsatisfactory; a keto-phosphonic acid was obtained but in very small amounts. Phosphenyl chloride, however, gave fair yields. The structure of the product was shown by oxidation with ozone. Benzaldehyde was obtained in large quantities. The reaction thus takes place as shown below, the addition being 1,4 and not 1,6 .

$\mathrm{C}_{6} \mathrm{H}_{5} \mathrm{CH}=\mathrm{CHCH}=\mathrm{CHCOC}_{6} \mathrm{H}_{5}+\mathrm{C}_{6} \mathrm{H}_{5} \mathrm{PCl}_{2}+2 \mathrm{CH}_{3} \mathrm{COOH} \rightarrow \mathrm{C}_{6} \mathrm{H}_{5} \mathrm{CH}=$ ${ }_{\mathrm{C}_{6} \mathrm{H}_{5} \mathrm{PO}_{2} \mathrm{H}}^{\mathrm{CHCHCH}} \mathrm{COC}_{6} \mathrm{H}_{5}+2 \mathrm{CH}_{3} \mathrm{COCl}$

\section{Experimental.}

$\alpha$ - Phenyl - $\beta$ - cinnamoyl - ethyl - phosphonic Acid, $\mathrm{C}_{6} \mathrm{H}_{5} \mathrm{CH}\left(\mathrm{PO}_{3} \mathrm{H}_{2}\right) \mathrm{CHCOCH}=$ $\mathrm{CHC}_{6} \mathrm{H}_{5}$. - This substance was prepared as previously described ${ }^{2}$ by the action of phosphorus trichloride on dibenzal-acetone in glacial acetic acid. In attempting to prepare considerable quantities of this acid it was found desirable to crystallize it from hot dil. acetic acid. Considerable amounts of some oily impurities were thus eliminated and the pure acid containing 1.25 mols. of water of crystallization was obtained. The yields were low; about $25 \%$ being the average. The rest of the material was apparently converted into some other acidic substance which could not be obtained in crystalline condition.

The acid is not decomposed by alcoholic potassium hydroxide solution either hot or cold. A crystalline potassium sal: separates, from which the acid may be obtained by treatment with acid.

Attempts to add another molecule of phosphorus trichloride to this unsaturated ketonic acid failed. Both acetic arid and anhydride were employed as mediums but the monophosphonic acid was recovered unchanged after treatment of the reaction mixture with water. In one experiment the reaction mixture was heated to somewhat below $100^{\circ}$. On treatment with water no unchanged monophosphonic acid could be obtained; the entire product was soluble in water. This points to the formation of a diphosphonic acid, but no substance could be isolated from the water solution.

$\alpha$ - Phenyl - $\beta$ - cinnamoyl - ethyl - phenylphosphonic Acid, $\mathrm{C}_{6} \mathrm{H}_{6} \mathrm{CH}\left(\mathrm{C}_{6} \mathrm{H}_{5} \mathrm{PO}_{2} \mathrm{H}\right)-$ $\mathrm{CHCOCH}=\mathrm{CHC}_{6} \mathrm{H}_{5}$. -Five $\mathrm{g}$. of dibenzal-acetone was suspended in $5 \mathrm{cc}$. of glacial acetic acid, and $3 \mathrm{cc}$. (one equivalent) of phosphenyl chloride was added to the mixture. On standing a few moments the ketone dissolved and the fumes of acetyl chloride were noticeable. Within 5 minutes the mixture solidified. The solid was then dissolved by treatment with an excess of $20 \%$ sodium hydroxide solution. The aqueous solution was extracted with ether to remove any unchanged ketone and the phosphonic acid precipitated by the addition of hycirochloric acid. The solid was filtered, washed with water and recrystallized from hot glacial acetic acid. The average yield was $53 \%$. The pure substance melts at 235 to $236^{\circ}$; it is almost insoluble in all common solvents.

Analysis. Calc. for $\mathrm{C}_{23} \mathrm{H}_{21} \mathrm{O}_{8} \mathrm{P}:$ P, 8.3. Found: 8.1.

Oxidation with ozone.-One $\mathrm{g}$. of the acid was suspended in $50 \mathrm{cc}$. of chloroform, and a stream of ozonized oxygen bubbled through the mixture. The ozonized oxygen was

2 This Journal, 39, 2679 (1917). 
prepared by electrolysis and was analyzed from time to time by passing a certain amount of it through potassium iodide solution. The gas contained about $4 \%$ of ozone, but was not completely free from moisture in spite of passing through a tube of phosphorus pentoxide. The oxidation was considered as complete when about a $20 \%$ excess of the theoretical amount of ozone had been passed into the solution. The solvent was evaporated under diminished pressure at a temperature of $40^{\circ}$. The residue was then distilled with steam; $0.2 \mathrm{~g}$. of benzaldehyde was thus obtained and identified by converting into the phenylhydrazone. The residue in the flask consisted of a water solution and a small amount $(0.18) \mathrm{g}$. of gummy material. The water solution on evaporation yielded $0.4 \mathrm{~g}$. of a crystalline solid melting at $212^{\circ}$.

$\alpha$-Phenyl- $\beta$-carboxy-ethyl-phenylphosphonic Acid, $\mathrm{C}_{6} \mathrm{H}_{5} \mathrm{CH}\left(\mathrm{C}_{8} \mathrm{H}_{6} \mathrm{PO}_{2} \mathrm{H}\right) \mathrm{CH}_{2} \mathrm{CO}_{2} \mathrm{H}$. --This acid, obtained as just indicated, could be recrystallized from hot water; it melted at $212^{\circ}$ Titration with $0.2 \mathrm{~N}$ sodium hydroxide solution showed it to be a dibasic acid with a molecular weight of 289 (calculated 290 ).

Analysis. Calc. for $\mathrm{C}_{15} \mathrm{H}_{15} \mathrm{O}_{4} \mathrm{P}: \quad \mathrm{P}, 10.7$. Found: 10.8 .

$\alpha$-Phenyl- $\beta$ (dibromo-hydrocinnamoyl)-ethyl-phosphonic Acid, $\mathrm{C}_{6} \mathrm{H}_{5} \mathrm{CH}\left(\mathrm{PO}_{3} \mathrm{H}_{2}\right.$ ) $\mathrm{CH}_{2} \mathrm{COCHBrCHBrC} \mathrm{H}_{5}$. - This substance was prepared by the action of bromine on a chloroform solution of the corresponding unsaturated phosphonic acid. The reaction is accelerated by sunlight; no hydrogen bromide is evolved. The product crystallizes from moist chloroform or aqueous alcobol in fine white needles melting with decomposition at 180 to $182^{\circ}$. They contain $2.5 \mathrm{mols}$. of water of erystallization. The anhydrous material could be obtained as an oil by working in absolutely dry chloroform or by heating a suspension of the hydrated material in chloroform together with anhydrous calcium chloride. Since the dibromide on heating loses hydrobromic acid as well as water, no direct determination of the water of crystallization was possible. The hydrated material is not soluble in chloroform but can be crystallized from aqueous alcohol.

Analysis. Calc. for $\mathrm{C}_{17} \mathrm{H}_{17} \mathrm{PO}_{4} \mathrm{Br}_{2}+2.5 \mathrm{H}_{2} \mathrm{O}: \mathrm{Br}, 30.7$. Found: $30.7,30.6,30.8$. $\alpha$-Phenyl- $\beta$ - $\alpha$-bromo-cinnamoyl)-ethyl-phosphonic Acid, $\mathrm{C}_{6} \mathrm{H}_{5} \mathrm{CH}\left(\mathrm{PO}_{3} \mathrm{H}_{2}\right) \mathrm{CH}_{2}$. $\mathrm{COCBr}=\mathrm{CHC}_{6} \mathrm{H}_{5}-7 \mathrm{~g}$. of the crude crystalline dibromide was suspended in 150 ce. of $95 \%$ alcohol and treated with a solution of $3 \mathrm{~g}$. of potassium hydroxide in 100 cc. of $95 \%$ alcohol. The mixture was allowed to stand for 2 hours; a considerable amount of potassium bromide separated. The solution was then diluted with an equal volume of water. The small precipitate of dibenzal-acetone $(0.1 \mathrm{~g}$.) which formed was filtered off. (This substance was produced by the action of the excess of potassium hydroxide on the monobromide as described later.) The filtrate was acidified and the monobromide precipitated in the form of fine needle crystals. They were recrystallized from aqueous alcohol containing a little acetic acid. $4.5 \mathrm{~g}$. was thus obtained, a yield of $81 \%$. The material thus prepared contains water of crystallization; it melts with the loss of this water at 130 to $132^{\circ}$. It is readily soluble in sodium hydrogen carbonate solution without decomposition. It reduces alkaline potassium permanganate solution instantly but does not combine with bromine. Titration with $0.5 \mathrm{~N}$ sodium hydroxide solution showed it to be a dibasic acid.

Analysis. Calc. for $\mathrm{C}_{17} \mathrm{H}_{16} \mathrm{O}_{4} \mathrm{BrP}+1 \mathrm{H}_{2} \mathrm{O}: \mathrm{Br}, 19.4$. Found: 19.5, 19.4 .

A sample of the acid was heated to constant weight at $135^{\circ}$ and the resulting melt analyzed for bromine.

Analysis. Calc. for $\mathrm{C}_{17} \mathrm{H}_{16} \mathrm{O}_{4} \mathrm{BrP}: \mathrm{Br}, 20.2$. Found: 20.3 .

A sample of the dehydrated material was dissolved in dry ether and saturated with hydrogen bromide. On evaporation an oil was left, which, on treatment with $50 \%$ aqueous alcohol yielded the crystalline dibromide previously described. It was identified by a mixed-melting-point determination.

Oxidation with Ozone.--One g. of the monobromide was heated to constant weight at $1.20^{\circ}$ and then dissolved in dry chloroform. The solution was treated with ozonized 
oxygen in the manner previously described. The solution became red during the process due to the formation of free bromine. This was apparently formed by the hydrolysis of the acid bromide and oxidation of the hydrogen bromide by the ozone. At the end of the oxidation the solution contained a solid which was filtered off; it weighed $0.35 \mathrm{~g}$. ( $50 \%$ yield). The chloroform solution was divided into two parts. One part was shaken with water and the aqueous layer tested for hydrobromic acid which was found to be present in large amount. The other half was evaporated and the residue distilled with steam; no benzaldehyde could be detected, but $0.1 \mathrm{~g}$. of benzoic acid was obtained by crystallization from hot water. The free bromine apparently oxidized the aldehyde to the acicl.

$\alpha$-Phenyl-p-glyoxy-ethyl-phosphonic Acid, $\left.\mathrm{C}_{6} \mathrm{H}_{6} \mathrm{CHPO}_{3} \mathrm{H}_{2}\right) \mathrm{CH}_{2} \mathrm{COCO}_{2} \mathrm{H}+2 \mathrm{H}_{2} \mathrm{O}$. -The solid which separated from the ozonized solution melted at $183^{\circ}$ with decomposition. Titration with $0.2 \mathrm{~N}$ sodium hydroxide solution showed that it was a tribasic acid with a molecular weigit of 297 ; the calculated molecular weight is 294 .

Analysis. Calc. for $\mathrm{C}_{10} \mathrm{H}_{11} \mathrm{O}_{6} \mathrm{P} .2 \mathrm{H}_{2} \mathrm{O}: \mathrm{P}, 10.5$. Found: 10.4 .

A sample of the acid was heated to constant weight at $120-125^{\circ}$ and then an alyzed.

Analysis. Calc. for $\mathrm{C}_{9} \mathrm{H}_{13} \mathrm{O}_{5} \mathrm{P}: \mathrm{P}, 13.5$. Found: 13.2 .

This shows that the ketonic acid on heating loses carbon monoxide and water and yields the acid $\mathrm{C}_{6} \mathrm{H}_{5} \mathrm{CH}\left(\mathrm{PO}_{3} \mathrm{H}_{2}\right) \mathrm{C}_{2} \mathrm{H}_{2} \mathrm{CO}_{2} \mathrm{H}$.

$\alpha$-Phenyl- $\beta$-(dibromo-hydrocinnamoyl)-ethyl-phenylphosphonic Acid.-Five g. of the unsaturated monobasic phosphonic acid was suspended in chloroform and treated with bromine. The color of the bromine disappeared rapidly and no hydrobromic acid was evolved; after standing several hours the crystalline dibromide separated. The yield was almost quantitative. On recrystallization from hot glacial acetic acid, however, some material was lost; m. p. $195^{\circ}$ with decomposition. The acid dissolves slowly in cold sodium hydrogen carbonate or carbonate solution and may be precipitated unchanged.

Analysis. Calc. for $\mathrm{C}_{23} \mathrm{H}_{21} \mathrm{O}_{i} \mathrm{Br}_{2} \mathrm{P}: \mathrm{Br}, 29.8$. Found: 29.6 .

$\alpha$-Phenyl- $\beta$-( $\alpha$-bromo-cinnamoyl)-ethyl-phenylphosphonic Acid.-The dibromide was dissolved in a hot $4 \%$ solution of potassium acetate in methyl alcohol. The solution was heated on the steam-bath for a few minutes and then poured into water. A clear solution resulted which on acidification yielded a crystalline precipitate of the monobromide. The yield was $80 \%$; m. p. $200^{\circ}$.

Analysis. Calc. for $\mathrm{C}_{28} \mathrm{H}_{20} \mathrm{O}_{3} \mathrm{PBr}$ : $\mathrm{Br}, 17.6$. Found: 17.6 .

Oxidation with Ozone. - The raonobromide is almost insoluble in chloroform so that a suspension had to be used for the oxidation. Ozonized oxygen was passed through the mixture for many hours in order to complete the oxidation. $0.3 \mathrm{~g}$. of material was oxidized in this way and the chloroform solution then extracted twice with water. The amount of hydrogen bromide in the aqueous layer was determined by the Volhard method.

Analysis. Calc. amount of bromide ion: $0.051 \mathrm{~g}$. Found: $0.044 \mathrm{~g}$. or $86 \%$.

In another experiment $0.6 \mathrm{~g}$. was ozonized and the chloroform solution extracted several times with water. The aqueous solution on evaporation to small volume yielded $0.17 \mathrm{~g}$. of the dibasic acid melting at $212^{\circ}$, which was previously obtained by the oxidation of the unsaturated phosphonic acid. The identity of the material was established by mixed-melting-point determinations and titration with standard alkali.

A small amount of benzoic acid was obtained by evaporation of the original chloroform solution.

The Action of Alkaline Reagents on the Monobromides.

Sodium hydrogen carbonate and sodium carbonate solutions dissolve 
both monobromides without decomposition. On acidification the original material is recovered unchanged.

Aqueous $10 \%$ potassium hydroxide dissolves both monobromides but the solution soon becomes colored and the odor of benzaldehyde can be detected after the mixture has stood some minutes; small amounts of unsaturated ketone sometimes separate from the solution of the dibasic monobromo acid. No product except benzaldehyde could be identified with the monobasic monobromo acid. On acidification with nitric acid and addition of silver nitrate a heavy precipitate of silver bromide is obtained in every case.

Alcoholic potassium hydroxide rapidly decomposes both monobromides. The solutions become yellow and finally deep red; the odor of benzaldehyde is very evident. On dilution with water dibenzal-acetone is obtained in the case of the dibasic acid; no definite product could be isolated in similar experiments with the monobasic acid. A typical experiment with the dibasic monobromo acid as follows.

$0.5 \mathrm{~g}$. of monobromide was added to $20 \mathrm{cc}$. of $95 \%$ alcohol containing $0.33 \mathrm{~g}$. of dissolved potassium hydroxide. The solution turned yellow, and finally at the end of one hour, deep red. Potassium bromide was precipitated. The odor of benzaldehyde was noticed. After standing overnight the solution was diluted with three times its volume of water. A very fine crystalline precipitate of dibenzal-acetone separated and was filtered off and dried; $0.08 \mathrm{~g}$. was thus obtained which is equivalent to $0.14 \mathrm{~g}$. of the monobromide or $28 \%$ of the material used. It was identified by a mixed-melting-point determination.

$\alpha$-Styryl- $\beta$-benzoyl-ethyl-phosphonic Acid, $\mathrm{C}_{6} \mathrm{H}_{5} \mathrm{CH}=\mathrm{CHCH}\left(\mathrm{PO}_{3} \mathrm{H}_{2}\right) \mathrm{CH}_{2}$ $\mathrm{COC}_{8} \mathrm{H}_{5}$. - No satisfactory results could be obtained by using acetic acid as a medium for adding phosphorus trichloride to cinnamylidene-acetophenone. Acetic anhydride was therefore employed. $15 \mathrm{~g}$, of the ketone was dissolved by gently warming in $15 \mathrm{~g}$. of acetic anhydride. $18 \mathrm{~g}$. of phosphorus trichloride was added to the warm solution and the flask gently warmed several times to the temperature at which acetyl chloride started to boil from the solution. The product after standing for 3 hours at room temperature was poured into $1800 \mathrm{cc}$. of wate:. The major portion of the product (about $10 \mathrm{~g}$.) separated as an oil which could not be obtained in crystalline condition. It was completely soluble in sodium carbonate solution and was reprecipitated by acids. It was evidently a mixture of phosphonic acids but no definite substances could be isolated from it. The aqueous solution was decanted from the oil and evaporated to a smal1 volume. About $1 \mathrm{~g}$. of crystalline material was obtained which melted at 159 to $161^{\circ}$. It was soluble in sodium hydrogen carbonate and was oxidized by potassium permanganate solution with the formation of benzaldehyde. It decolorized a chloroform solution of bromine only slowly

Analyses. Calc. for $\mathrm{C}_{17} \mathrm{H}_{17} \mathrm{O}_{4} \mathrm{P}, 1 / 4 \mathrm{H}_{2} \mathrm{O}: \mathrm{C}, 63.6: \mathrm{H}, 5.5 ; \mathrm{P}, 9.8$. Found: C, 63.7; $\mathrm{H}, 5.7 ; \mathrm{P}, 9.7$.

$\alpha$-Styryl- $\beta$-benzoyl-ethyl-phenylphosphonic Acid, $=\mathrm{C}_{6} \mathrm{H}_{5} \mathrm{CH} \mathrm{CHCH}\left(\mathrm{C}_{6} \mathrm{H}_{6} \mathrm{PO}_{2} \mathrm{H}\right)$ $\mathrm{CH}_{2} \mathrm{COC}_{6} \mathrm{H}_{5}$. - Twenty $\mathrm{g}$. of cinnamylidene-acetophenone was suspended in $20 \mathrm{cc}$. of glacial acetic acid, and $12 \mathrm{cc}$. of phosphenyl chloride was added. The ketone slowly dissolved. At the end of 3 hours the mixture was almost solid. The material was treated with water, the solid filtered and recrystallized from hot glacial acetic acid. 
$20.5 \mathrm{~g}$. of recrystallized product was obtained,-a yield of $64 \%$. The solid melts at $200^{\circ}$. It is insoluble in most solvents.

Analysis. Calc. for $\mathrm{C}_{23} \mathrm{H}_{21} \mathrm{O}_{3} \mathrm{P}: \mathrm{P}, 8.24$. Found: 8.26.

Oxidation with ozone.-One $\mathrm{g}$. of the material was suspended in chloroform and treated with ozonized oxygen for the calculated length of time. The solvent was evaporated and the residue distilled with steam. $0.22 \mathrm{~g}$. of benzaldehyde was thus obtained, and $0.1 \mathrm{~g}$. of unoxidized material was found in the residue. The amount of benzaldehyde found is thus about $90 \%$ of the amount that could theoretically be obtained from the $0.9 \mathrm{~g}$. of material which was ozidized. In another experiment the residue left after evaporation of the solvent was treated with sodium carbonate solution and filtered from a small amount of oil. On acidification with nitric acid a dark flocculent precipitate was formed. It could not be obtained pure enough for analysis, but it was obviously an acid and contained phosphorus.

\section{Summary.}

1. Phosphorus trichloride: and phosphenyl chloride combine with dibenzal-acetone in glacial acetic acid to form unsaturated keto-phosphonic acids.

2. The unsaturated acids thus formed combine with two atoms of bromine and form dibromides. The dibromides on treatment with alkaline reagents easily losse hydrogen bromide and form monobromo acids. The structure of these monobromides was established by oxidation with ozone.

3. The monobromides are easily decomposed by aqueous and alcoholic potassium hydroxide. Benzaldehyde is formed. In the case of one of the monobromides about $25 \%$ of dibenzal-acetone is also produced.

4. Unsaturated keto-phosphonic acids are formed by the action of phosphorus trichloride and phosphenyl chloride on cinnamylidene-acetophenone in suitable solvents. The combination takes place in the 1,4 position as shown by oxidation with ozone.

Cambridge 38, Massachusetts.

\section{THE ACTION OF HYDROGEN PHOSPHIDE ON FORMALDEHYDE.}

\section{BY ALFRED HOFFMAN.}

Received April 18, 1921.

The condensation of hydrogen phosphide with aldehydes was studied by Messinger and Engels. ${ }^{1}$ By passing a mixture of hydrogen phosphide and dry hydrogen chloride into ethereal solutions of the aldehydes they obtained compounds of the composition (R.CHO) ${ }_{4} \mathrm{PH}_{4} \mathrm{Cl}$. Treated with potassium hydroxide these gave products assumed by the authors to be mixtures of the free phosphine and its hydrate. Similar compounds have been prepared by Girard, ${ }^{2}$ by the action of phosphonium iodide on aldehydes. Formaldehyde was not investigated by either of these authors.

1 Messinger and Engels, Ber., 21, 325 (1888).

2 Girard, Ann. chim., [6] 2, 2 (1884). 